\title{
Issues in Civil Society in a Cosmopolitan World
}

The papers in this issue of the Cosmopolitan Civil Societies Journal explore the theme of civil society, community organisations and national governments in a wide and varied range of social and political contexts. The papers document and explore diverse roles taken by civil society in different conditions and circumstances in a number of geographic locations. The first two papers deal with displacement and the increase in this problem that will occur due to climate change. Displacement is difficult not only for those who have to relocate and it is likely to be a challenging process for all involved, including national governments and civil society. A range of other difficult issues are addressed by the other papers in the issue, including combatting child sex-trafficking, rebuilding a post-genocide society and building social capital among Turkish women with low socio-economic status. Each paper highlights the different roles civil society can play in these diverse situations to improve the well-being of vulnerable people and communities.

The first paper, by Vinnitta Patricia Mosby, presents a methodology useful in exploring issues facing the indigenous people of the Torres Strait Islands. A culture and civilisation that has survived on these islands, which are located at the northern tip of eastern Australia, for thousands of years is now being threatened by adverse effects of climate change, particularly rising sea levels. Migration from the islands is not new; however, the rate of displacement is likely to continue to increase. The research methodology shows the importance to other islanders displaced by climate change of staying connected to self, family and culture as they move from their island.

Continuing the theme of environmental migration, Gil Marvel P.Tabucanon's paper explores the role the ASEAN countries could take to assist the vulnerable Pacific populations facing the possibility of relocation. The paper also explores the emerging issue of environmental refugees and the response to this issues in various countries, both within ASEAN and elsewhere. These are challenging issues which will become even more severe as global temperatures and sea levels rise. 
The third paper explores people movement of different kind. Deanna Davy's research focuses on the role of transnational anti-trafficking advocacy networks in combatting child sex trafficking in the Greater Mekong Subregion. It uses cosmopolitan globalisation theory to explore the active role taken by civil society to counter global social problems, such as trafficking.

The recovery from the extreme social problem of the genocide in Rwanda is the focus of paper by Gerise Herndon and Shirley Randell. It focuses on the roles of civil society organizations in rebuilding the country following the trauma of the 1994 genocide. It examines the role of women in Rwandan social and political life, where they represent $56 \%$ of the members of the Parliament. This high level of political representation, however, has not translated to women's empowerment in other parts of Rwandan society. The reasons for this and how the obstacles to gender equality might be overcome are explored in the paper.

The final paper continues the focus on women, however, in a completely different context. Gizem Arat, Arzu Icağasığlu-Çoban and Gonca Polat examine the factors contributing to the formation of social capital among Turkish women with low socio-economic status through community centres in Ankara. Both the Rwandan and Turkish paper show the important role women play in the maintenance and development of strong communities.

The five papers provide new perspectives within these different contexts on the emerging and changing role of civil society around the world. It plays an important role in migration, combatting global problems and assisting women develop their communities. We are sure that these papers will make a useful contribution to the knowledge of civil society and the Journal would welcome further scholarly contributions in these and other areas related to cosmopolitan civil societies across the globe.

Dr Ian McGregor 